\title{
Oxidative Stress in the Critically Ill Polytrauma Patient
}

\author{
Dorel Săndesc*
}

Anesthesia and Intensive Care Clinic, Emergency County Hospital "Pius Brînzeu", Timișoara, Romania; Faculty of Medicine, "Victor Babeș" University of Medicine and Pharmacy, Timișoara, Romania

The critically ill patient with primary multiple traumas and having secondary complications, presents a complex challenge to the trauma team. The most commonly encountered primary injuries are traumatic brain, spinal cord, pulmonary and abdominal injuries or trauma to the pelvis and the extremities. Moreover, severe inflammations, infections, hyper-metabolism, as well as biochemical and physiological imbalances, lead to a significant increase in morbidity and mortality.

Most recently, the role of free radicals has been a largely debated and reported topic. Once produced in excess, free radicals are responsible for inducing oxidative stress. The redox species known to have a destructive effect on cells include the superoxide anion, the hydroxyl radical, hydrogen peroxide, nitric oxide, peroxynitrite, lipid peroxyl and alkoxy lipid. Under normal conditions, free radicals are produced in the human body in small amounts, their activity being minimized by the body's physiologically anti-oxidant systems which include superoxide dismutase, catalase, glutathione, glutathione peroxidase, peroxiredoxins, and glutaredoxins.

In the critically ill patient, severe physiological and biochemical imbalances significantly reduce the body's anti-oxidant capacity, disrupting the redox balance [1]. A series of biomarkers are in use, designed to quantify oxidative stress. These comprise interleukin 1 beta, interleukin 6, interleukin 10, tumor necrosis alpha, components of the complement, plasmatic levels of antioxidant enzymes and the microRNA species [2].

Oxidative stress in the polytrauma patient is produced shortly after the initial trauma. Subsequently, it transfers from the macroscopic level to the cellular level and thereafter to the molecular level. At this level, the oxidative stress is enhanced and self-sustained, generating a second wave of injury which is then responsible for a systemic inflammatory response syndrome (SIRS) and for the excessive biosynthesis of free radicals.

In the critically ill patient with multiple traumas, these events are manifest by the patient becoming vulnerable to microbial grafting. The multiplication of pathogenic germs, immunosuppression and increased levels of pro-inflammatory molecules frequently leads to sepsis and despite intensive treatment, progresses to multiple organ dysfunction syndrome (MODS) and death.

The implications of the oxidative stress in the critically ill polytrauma patient has been the subject of a number of recent reports. Hohl reported a statistically significant correlation between plasma levels of specific biomarkers for oxidative injury with a number of clinical variables, in their study on oxidative stress in patients with traumatic brain injury [3].

Nathens [4], in a similar study, reported a series of statistically significant correlations regarding oxidative stress in patients with pulmonary trauma. Moreover, the reduction of a systemic inflammatory response in these patients, following the administration of substances with high anti-oxidant capacity, was highlighted in these studies.

A high percentage of the patients with multiple trauma present with haemorrhagic shock as a consequence of centralisation of the circulation in order to protect vital organs. Blockage in the micro-circulation ensues, followed by tissue hypo-oxygenation in organs with reduced blood flow [5-8]. Simultaneously, a systemic inflammatory response syndrome is triggered, modulated by trauma intensity and the genetic predisposition of each individual patient $[9,10]$.

Crime [11] highlighted the decrease in required time on a mechanical ventilation and in mortality rates, in critically ill patients with multiple trauma who have 
received intravenous vitamin C [500 $\mathrm{mg} /$ day] and 400 IU/day of Vitamin E. Collier [12] also reported the importance of implementing anti-oxidant therapy in the critically ill patient.

The overall conclusion derived from these studies is that the antioxidant therapy most used in intensive care units consists of Vitamin C, Vitamin E, Vitamin B6, Vitamin B12, Resveratrol and N-Acetylcysteine in various ratios and concentrations, and that the administration of these drugs, to the critically ill polytrauma patient, results in a decrease in the mortality rate and in the length of stay both in an intensive care unit and a hospital [13].

In this issue, implications of oxidative stress in the critically ill patient with severe head injury are presented in an article by Luca and its research group [14], following numerous publications on the subject $[15,16]$.

In spite of the interesting and important results reported on the beneficial effects of administration of substances with high antioxidant capacity in instances of oxidative stress, the reader is reminded that there are other studies that do not highlight any changes in the clinical development of the critically ill polytrauma patient under similar drug regimes, indicative of the need for further studies in this area.

\section{DEFERENCES}

1. Hybertson BM, Gao B, Bose SK, McCord JM. Oxidative stress in health and disease: The therapeutic potential of Nrf2 activation. Mol Aspects Med. 2011;32:234-46.

2. Mendes Arent A, Souza LF De, Walz R, Dafre AL. Perspectives on molecular biomarkers of oxidative stress and antioxidant strategies in traumatic brain injury. Biomed Res Int. 2014; 2014:723060

3. Hohl A, Gullo JDS, Silva CCP, et al. Plasma levels of oxidative stress biomarkers and hospital mortality in severe head injury:
A multivariate analysis. J Crit Care. 2012;27:523.e.11-9.

4. Nathens AB, Neff MJ, Jurkovich GJ, et al. Randomized, prospective trial of antioxidant supplementation in critically ill surgical patients. Ann Surg. 2002;236:814-22.

5. Marik PE. The optimal endpoint of resuscitation in trauma patients. Crit Care. 2003;7:19-20.

6. Flörchinger B, Philipp A, Klose A, et al. Pumpless Extracorporeal Lung Assist: A 10-Year Institutional Experience. Ann Thorac Surg. 2008;86:410-7.

7. Bar-Or D, Bar-Or R, Rael LT, Brody EN. Oxidative stress in severe acute illness. Redox Biol. 2015;4:340-5.

8. Erecinska M, Thoresen M, Silver I. Effects of hypothermia on energy metabolism in Mammalian central nervous system. J Cereb Blood Flow Metab. 2003;23:513-30.

9. Bosmann M, Ward PA. The inflammatory response in sepsis. Trends Immunol. 2013;34:129-36.

10. Brodska H, Valenta J, Malickova K, Kohout P, Kazda A, Drabek T. Biomarkers in critically ill patients with systemic inflammatory response syndrome or sepsis supplemented with high-dose selenium. J Trace Elem Med Biol. 2015;31:25-32.

11. Crimi E, Sica V, Williams-Ignarro $S$, et al. The role of oxidative stress in adult critical care. Free Radic Biol Med. 2006; 40:398406.

12. Collier BR, Giladi A, Dossett LA, Dyer L, Fleming SB, Cotton BA. Impact of High-Dose Antioxidants on Outcomes in Acutely Injured Patients. J Parenter Enter Nutr. 2008 ;32:384-8.

13. Oudemans-van Straaten HM, Man A, de Waard MC. Vitamin C revisited. Crit Care. 2014;18:460.

14. Luca L, Rogobete AF, Bedreag $\mathrm{OH}$. Oxidative stress and antioxidant therapy in critically ill polytrauma patients with severe head injury. J Crit Care Med. 2015;1:83-91.

15. Bedreag $\mathrm{OH}$, Rogobete $A F$, Sărăndan $M$, et al. Oxidative stress and antioxidant therapy in traumatic spinal cord injuries. J Rom Anest Terap Int. 2014;21:123-9.

16. Bedreag $\mathrm{OH}$, Rogobete $\mathrm{AF}$, Sarandan $\mathrm{M}$, et al. Oxidative stress in severe pulmonary trauma in critical ill patients. Antioxidant therapy in patients with multiple trauma - a review. Anestezjol Intens Ter. 2015. doi: 10.5603/AIT.a2015.0030. [Epub ahead of print] 